\title{
CHARACTERIZATION OF CEMENT-BASED COMPOSITE EXPOSED TO HIGH TEMPERATURES VIA ULTRASONIC PULSE METHOD
}

\author{
Iva Rozsypalová*, Michal Vyhlídal, Richard Dvořák, Tomáš Majda, \\ Libor Topolář, Luboš Pazdera, Hana Šimonová, ZbynĚK KerŠner
}

\author{
Brno University of Technology, Faculty of Civil Engineering, Veveři 331/95, 60200 Brno, Czech Republic \\ * corresponding author: Iva.Rozsypalova@vutbr.cz
}

\begin{abstract}
In this paper, the attention is paid to the investigation of the influence of high temperature acting on specimens made from specially designed cement-based composite. The experimental programme was carried out on six sets of beam specimens with the dimensions of $20 \times 40 \times 200 \mathrm{~mm}$. The specimens were loaded to a pre-set temperature of 100, 200, 400, 600, 800 and $1000{ }^{\circ} \mathrm{C}$ and then the temperature was kept for 60 minutes. When the temperature loading had been done, the specimens were left to cool down to the ambient temperature. After that, the ultrasonic pulse method was used to determine the degree of damage of temperature loaded specimens. The measured data obtained by this non-destructive method are in high correlation with values of informative compressive strength of the composite obtained after the temperature loading of specimens.
\end{abstract}

KEYWORDS: Fine-grained cement-based composite, glass spherical aggregate, high temperature, ultrasonic pulse method.

\section{INTRODUCTION}

Cement-based composites belong to the frequently used building materials for a wide range of applications [1, 2. Structures and construction components utilizing this composite were commonly designed assuming normal service temperatures. However, high temperatures acting on cement-based composite - for example during the fire etc. - cause a wide range of physical and chemical processes, which result in changes in the structure of composite and thus affects its mechanical properties [3, 4].

According to the theory of fracture mechanics, cement-based composites, in this case fine-grained cement-based composite, show quasi-brittle behaviour. Specimens made from these materials have the ability to carry the load even after the deviation from a linear branch of load-displacement diagram until the peak point and then the decrease of the loading force follows until the failure - see e.g. [5, 6]. One of the reasons for this behaviour could be the existence of the interfacial transition zone (ITZ). This well-known zone around aggregate particles of a few micrometers in size has the specific features. These are mainly higher porosity and calcium hydroxide contents compared to the bulk matrix [7-12].

The scope of this paper is to show the results of a pilot study which deals with the characterization of the damage degree of special cement-based composite specimens exposed to high temperatures via ultrasonic pulse method.

\section{EXPERIMENTAL PROGRAMME - MATERIALS, SPECIMENS, METHODS}

Three-part silicone moulds were made in plywood frame and subsequently used to produce the test specimens, see Figure 1] The test specimens were manufactured from the special designed fine-grained cementbased composite. The fresh mixture was made using the spherical sodium-potassium glass aggregates with a diameter of $2 \pm 0.2 \mathrm{~mm}$, Portland cement CEM I $42.5 \mathrm{R}$ (from cement plant Mokrá) and water in a ratio of $3: 1: 0.35$. The components were mixed in laboratory conditions using the standard mixer. After pouring and compaction of the fresh mixture, the moulds was sealed with a thin PE foil and placed in the stabilized laboratory conditions for 1 day, see Figure 2 After demoulding the test specimens had been stored in a water bath until their testing.

The experimental programme was carried out on six sets of specimens according to considered maximum temperature. Always, three test specimens with the nominal dimensions of $20 \times 40 \times 200 \mathrm{~mm}$ were prepared per each testing set. A laboratory furnace Classic type 5013 with 3 sides of heating coils was used to heat of test specimens. The temperature loading started at the laboratory temperature of $20{ }^{\circ} \mathrm{C}$. The specimens were loaded with the temperature rate of $5{ }^{\circ} \mathrm{C} / \mathrm{min}$ up to a pre-set temperature. The pre-set temperatures were $100{ }^{\circ} \mathrm{C}$ (reference temperature), $200{ }^{\circ} \mathrm{C}, 400{ }^{\circ} \mathrm{C}, 600{ }^{\circ} \mathrm{C}, 800{ }^{\circ} \mathrm{C}$, and $1000{ }^{\circ} \mathrm{C}$. The next part of the temperature-time curve was constant, i.e. the maximum temperature was kept for 60 minutes. After that, the specimens were left to cool down to the ambient temperature and had been placed in a room 

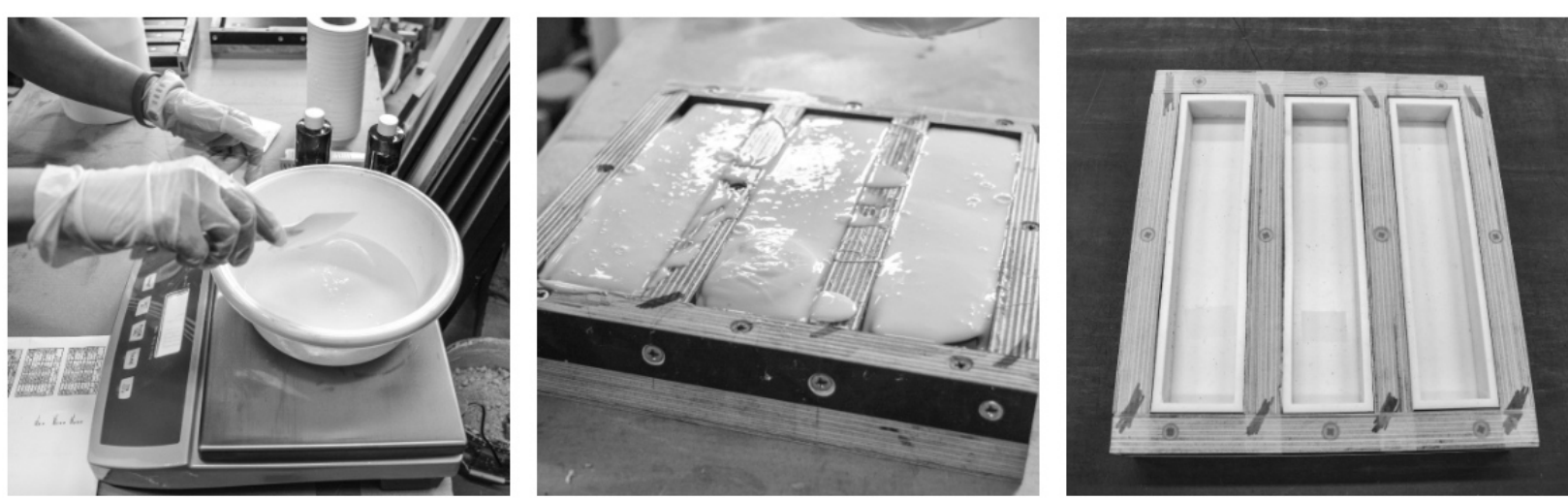

FIGURE 1. Illustration of silicone moulds preparing.
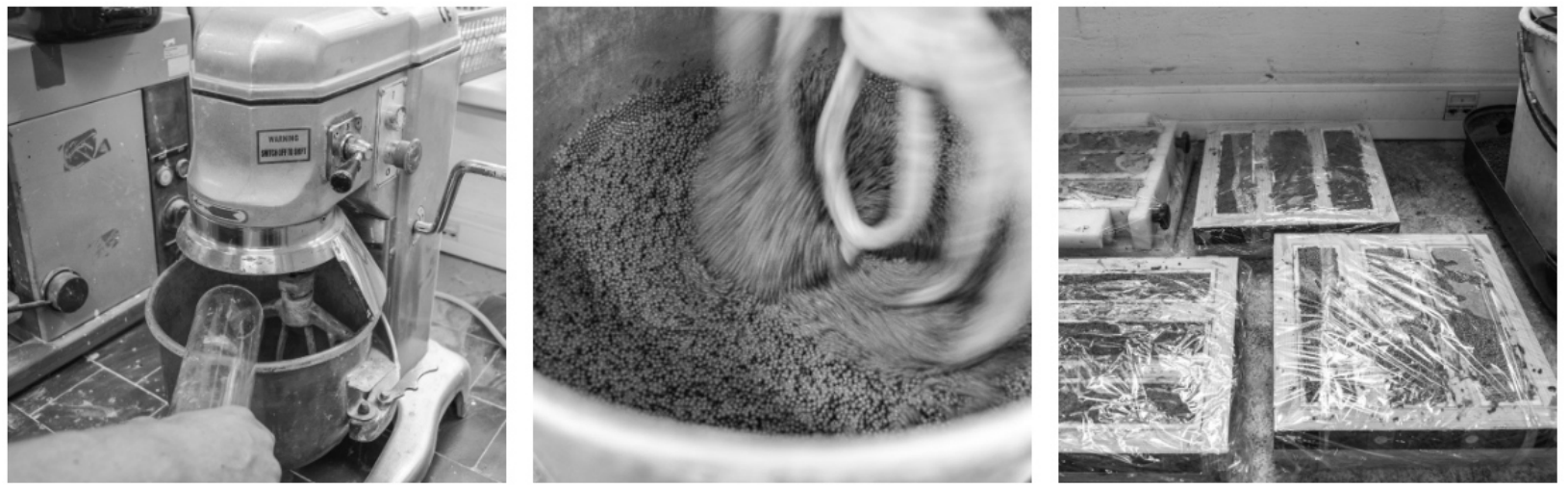

FigURE 2. Illustration of manufacture of test specimens.

with the temperature of $20{ }^{\circ} \mathrm{C}$. All specimens were tested by ultrasonic pulse method before and after the temperature loading performed at the laboratory temperature.

During the ultrasonic pulse method measurement, the specimens were excited by a sensor placed in the centre of side cross-section of specimen - transmitter $\mathrm{T}$ (see Figure 3). Impulses were generated by the pulse generator Agilent 33220A. The acoustic emission system XEDO was used to detect the waves. Three piezoelectric sensors were placed on different locations of the specimen surface, see Figure 3 The first sensor $\mathrm{S}_{1}$ was placed near the exciter on the perpendicular surface, the second one $\left(\mathrm{S}_{2}\right)$ on the opposite surface to the transmitter near the edge and the third sensor $\left(\mathrm{S}_{3}\right)$ was on the same surface as the first one but close to the opposite edge.

The generated signal can be in either form of continuous noise or harmonic signals [13. The evaluation of the signals response to the transmitted pulse in the tested object can be performed in two basic systems of analysis. In the first case, the resulting shift in relation to time is evaluated, and in the second case, the signals are converted to the frequency domain and a frequency analysis is performed. The results used in this paper are from the time domain.

Subsequently, all specimens were provided by an initial notch and selected specimens were tested in a three-point bending configuration. Selected specimens will be tested at the Centre of Excellence Telč, Czech Republic in the four-point bending configuration, and $\mathrm{X}$-ray computed tomography of these specimens is also planned - specimens are bellow marked CT. Analysis of results of these fracture tests are being prepared and they are not the matter of this paper.

The compressive strength value was determined at the parts of specimens obtained after the three-point bending fracture tests were performed. The auxiliary loading device with two (upper and lower) square steel auxiliary platens was placed in the hydraulic testing machine. The specimens were placed between the auxiliary plates in such a way that the load was applied perpendicularly to the compaction direction, as can be seen in Figure 4. The test was carried out in accordance with the principles of standards ČSN EN 196-1 [14] and BS 1881: Part 119 [15]. Increasing load was applied continuously until the failure when the loading force decrease. The maximum load applied to each specimen was recorded. The informative compressive strength value of material of the specimen was calculated by dividing the maximum load by the area of contact - nominal surface area $40 \times 20 \mathrm{~mm}^{2}$. 


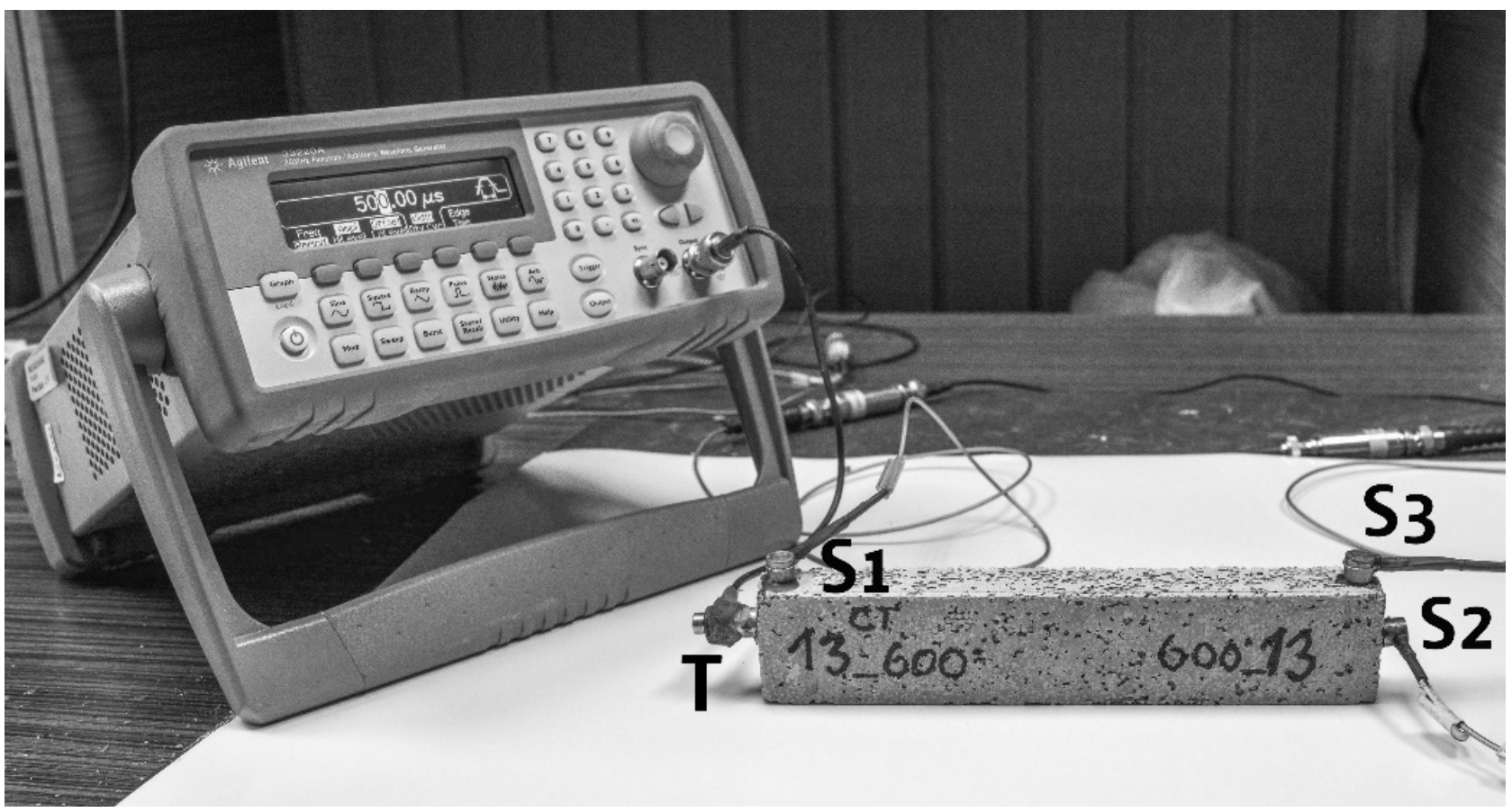

FigURE 3. Illustration of the ultrasonic pulse method experimental set-up (transmitter T, sensors $\mathrm{S}_{1}, \mathrm{~S}_{2}$, and $\mathrm{S}_{3}$ ).
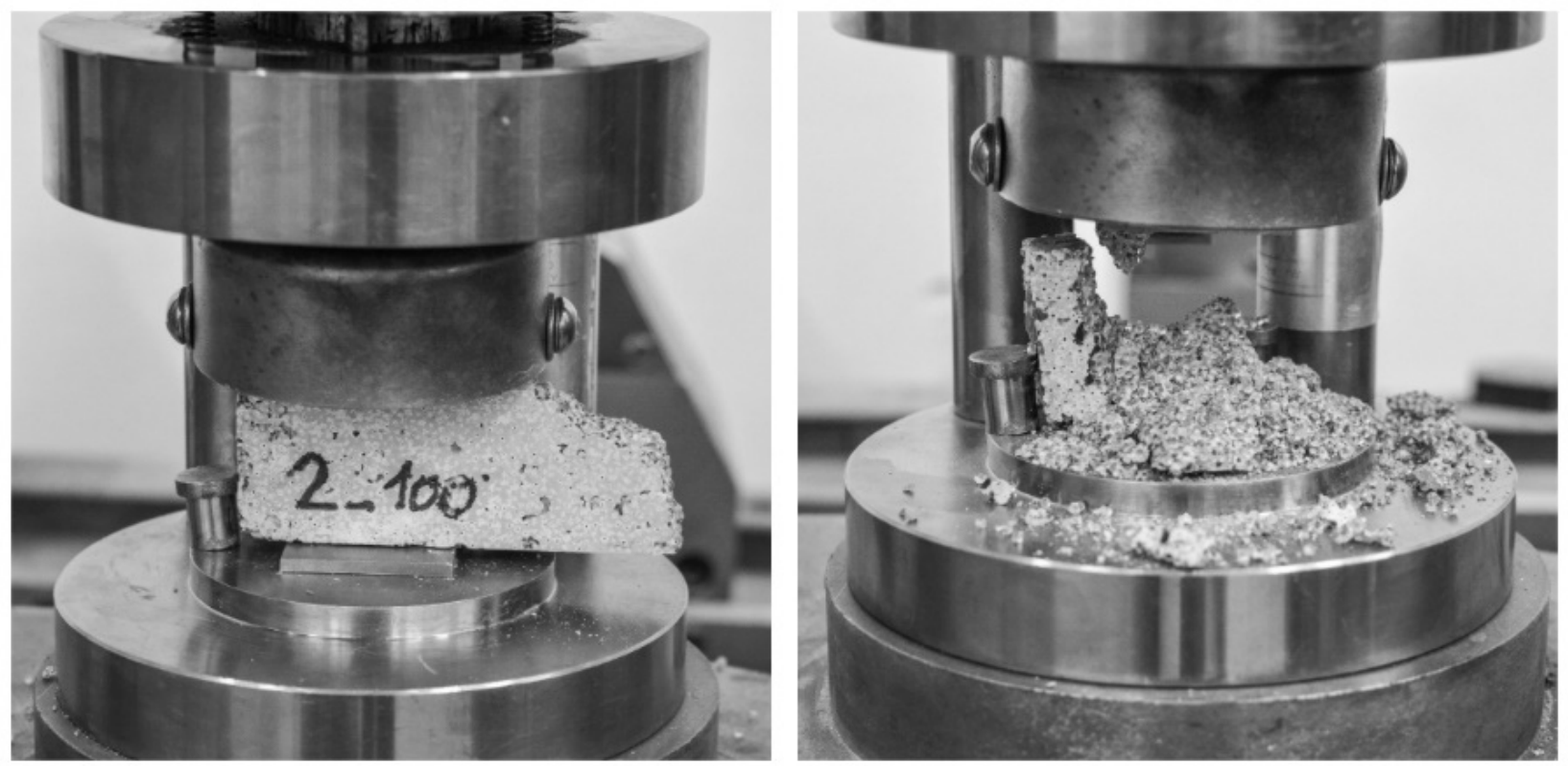

Figure 4. The compression test of specimens: The auxiliary loading device with two auxiliary platen was placed in the hydraulic testing machine with selected specimens prepared for the test (left); specimen after testing.

\section{Results}

All measured data, results of the ultrasonic pulse method and informative compressive strengths for test specimens are shown in Table 1 . Basic statistics mean values and standard deviations - of corrected selected data, as well as coefficients of correlation are introduced in Tables 2 and 3 The ratio between maximum amplitudes $r_{21}$ and $r_{31}$ is called signal attenuation at the constant length - numbers 1, 2 and 3 correspond to the sensors $\mathrm{S}_{1}, \mathrm{~S}_{2}$, and $\mathrm{S}_{3}$, index "b" or "a" means measurement before or after tempera- ture loading. The outcome of applied procedure is a proportion of ratio $r$ of temperature loaded specimen $\left(r_{21, a}\right.$ or $\left.r_{31, a}\right)$ to ratio $r$ of the non-degraded specimen $\left(r_{21, b}\right.$ or $\left.r_{31, b}\right)$ - labelled as $R_{21}$ and $R_{31}$, respectively.

\section{Conclusions}

After the exposure of cement-based composites to elevated temperatures their mechanical parameters are reduced [4]. Therefore, the presented paper was focused on the evaluation of the damage degree of finegrained cement-based composite specimens exposed 


\begin{tabular}{|c|c|c|c|c|c|c|c|c|c|}
\hline Specimen & $\begin{array}{c}\text { Bulk } \\
\text { density } \\
\gamma\end{array}$ & $\begin{array}{c}\text { Tempe- } \\
\text { rature } \\
T\end{array}$ & $\begin{array}{c}\text { Ratio } \\
r_{21, b}\end{array}$ & $\begin{array}{c}\text { Ratio } \\
r_{31, b}\end{array}$ & $\begin{array}{c}\text { Ratio } \\
r_{21, a}\end{array}$ & $\begin{array}{c}\text { Ratio } \\
r_{31, a}\end{array}$ & $\begin{array}{c}\text { Ratio } \\
R_{21}\end{array}$ & $\begin{array}{c}\text { Ratio } \\
R_{31}\end{array}$ & $\begin{array}{c}\text { Compres- } \\
\text { sive } \\
\text { strength } \\
\quad f_{c, i}\end{array}$ \\
\hline & $\mathrm{kg} \cdot \mathrm{m}^{-3}$ & ${ }^{\circ} \mathrm{C}$ & - & - & - & - & - & - & $\mathrm{MPa}$ \\
\hline 01-100 CT & 1912 & 100 & 0.0140 & 0.0276 & 0.0406 & 0.0545 & 2.900 & 1.975 & - \\
\hline 02-100 & 1875 & 100 & 0.0190 & 0.0527 & 0.0089 & 0.0146 & 0.468 & 0.278 & 4.61 \\
\hline 03-100 & 1847 & 100 & 0.0651 & 0.0425 & 0.0074 & 0.0113 & 0.114 & 0.266 & 3.58 \\
\hline 04-100 & 1906 & 100 & 0.0154 & 0.0154 & 0.0098 & 0.0153 & 0.640 & 0.993 & 8.21 \\
\hline 25 & 1925 & 100 & 0.0949 & 0.1391 & 0.0578 & 0.0916 & 0.609 & 0.659 & 6.03 \\
\hline 26 & 1958 & 100 & 0.3462 & 0.4216 & 0.1154 & 0.1450 & 0.333 & 0.344 & - \\
\hline 27 & 2009 & 100 & 0.2550 & 0.4041 & 0.0833 & 0.0816 & 0.327 & 0.202 & 8.44 \\
\hline 05-200 CT & 1912 & 200 & 0.0120 & 0.0289 & 0.0026 & 0.0111 & 0.217 & 0.384 & - \\
\hline 06-200 & 1988 & 200 & 0.0156 & 0.0206 & 0.0042 & 0.0121 & 0.270 & 0.587 & 6.91 \\
\hline $07-200$ & 1956 & 200 & 0.0262 & 0.0296 & 0.0081 & 0.0180 & 0.309 & 0.607 & 4.68 \\
\hline $08-200$ & 1844 & 200 & 0.0255 & 0.0216 & 0.0072 & 0.0071 & 0.282 & 0.327 & 7.73 \\
\hline 09-400 CT & 1958 & 400 & 0.0166 & 0.0200 & 0.0037 & 0.0025 & 0.223 & 0.125 & - \\
\hline $10-400$ & 1993 & 400 & 0.2805 & 0.4328 & 0.0375 & 0.0609 & 0.134 & 0.141 & 4.42 \\
\hline $11-400$ & 2020 & 400 & 0.1404 & 0.1638 & 0.0166 & 0.0239 & 0.118 & 0.146 & 4.29 \\
\hline $12-400$ & 1975 & 400 & 0.1546 & 0.1421 & 0.0232 & 0.0240 & 0.150 & 0.169 & 5.21 \\
\hline $13-600 \mathrm{CT}$ & 1951 & 600 & 0.0792 & 0.0748 & - & - & - & - & - \\
\hline $14-600$ & 1972 & 600 & 0.0799 & 0.0974 & - & - & - & - & 1.88 \\
\hline $15-600$ & 1997 & 600 & 0.1051 & 0.1930 & - & - & - & - & - \\
\hline $16-600$ & 2017 & 600 & 0.1448 & 0.1586 & - & - & - & - & 3.93 \\
\hline 17-800 CT & 1974 & 800 & 0.1554 & 0.1405 & - & - & - & - & - \\
\hline $18-800$ & 1942 & 800 & 0.1017 & 0.2213 & - & - & - & - & - \\
\hline $19-800$ & 1887 & 800 & 0.2204 & 0.1781 & - & - & - & - & - \\
\hline $20-800$ & 1899 & 800 & 0.0895 & 0.1810 & - & - & - & - & - \\
\hline 21-1000 CT & 1925 & 1000 & 0.0866 & 0.0901 & 1.5438 & 1.1155 & 17.82 & 12.38 & - \\
\hline $22-1000$ & 1953 & 1000 & 0.1186 & 0.1631 & 0.3696 & 0.4316 & 3.118 & 2.647 & 1.96 \\
\hline $23-1000$ & 1958 & 1000 & 0.1208 & 0.1438 & 0.6280 & 0.9794 & 5.200 & 6.809 & 1.67 \\
\hline $24-1000$ & 1987 & 1000 & 0.1259 & 0.1394 & 0.3037 & 0.3264 & 2.413 & 2.341 & 1.45 \\
\hline
\end{tabular}

TABLE 1. Measured data, results of the ultrasonic pulse method and informative compressive strengths.

\begin{tabular}{ccccc}
\hline Temperature $T$ & Bulk density $\gamma$ & Ratio $R_{21}$ & Ratio $R_{31}$ & Compressive strength $f_{c, i}$ \\
\hline${ }^{\circ} \mathrm{C}$ & $\mathrm{kg} \cdot \mathrm{m}^{-3}$ & - & - & $\mathrm{MPa}$ \\
\hline 100 & $1919(53)$ & $0.475(0.148)$ & $0.457(0.308)$ & $6.17(2.15)$ \\
200 & $1925(63)$ & $0.270(0.039)$ & $0.476(0.142)$ & $6.44(1.58)$ \\
400 & $1986(26)$ & $0.156(0.460)$ & $0.145(0.018)$ & $4.64(0.50)$ \\
600 & $1984(29)$ & - & - & $2.91(1.45)$ \\
800 & $1925(40)$ & - & - & - \\
1000 & $1956(25)$ & $3.577(1.449)$ & $3.933(2.496)$ & $1.69(0.26)$ \\
\hline
\end{tabular}

TABLE 2. Mean values (standard deviations) of selected data.

to high temperatures via ultrasonic pulse method.

Resulting data from this method are in quite high correlation with loading temperature (coefficient of correlation was in range 0.63 to 0.92 ), as well as with compressive strength of composite determined after the temperature loading (coefficient of correlation was in range -0.59 to -0.91 ). The very high correlation is between ratios $R_{21}$ and $R_{31}$ (coefficient of correlation was in range 0.97 to 1.00 ) which means that it is sufficient placed the sensors on the surface in the case of a large structure. The strong relationship between compressive strength and temperature for this special cement-based composite with spherical glass aggregates (coefficient of correlation was in range 


\begin{tabular}{cccccc}
\hline & $\gamma$ & $T$ & $R_{21}$ & $R_{31}$ & $f_{c, i}$ \\
\hline Bulk density $\gamma$ & 1.00 & & & & \\
Temperature $T$ & $0.23 \mid 0.29$ & 1.00 & & symm. & \\
Ratio $R_{21}$ & $-0.06 \mid 0.14$ & $0.63 \mid 0.92$ & 1.00 & & \\
Ratio $R_{31}$ & $-0.03 \mid 0.12$ & $0.70 \mid 0.92$ & $0.97 \mid 1.00$ & 1.00 & \\
Compressive strength $f_{c, i}$ & $-0.19 \mid-0.63$ & $-0.80 \mid-0.97$ & $-0.66 \mid-0.91$ & $-0.59 \mid-0.90$ & 1.00 \\
\hline
\end{tabular}

TABLE 3. Coefficients of correlation (dimensionless) of selected data: all values (Table 1) | mean values (Table 2 .

-0.97 to -0.80$)$ was confirmed in this study.

The ultrasonic pulse method as a non-destructive method seems to be well-suited for determining the damage degree caused by elevated temperature in case of this special cement-based fine-grained composite.

\section{LIST OF SYMBOLS}

$\gamma \quad$ Bulk density before temperature loading at temperatures higher than $100{ }^{\circ} \mathrm{C}$

$f_{c, i}$ Informative compressive strength

$r_{21, a}$ The ratio of the maximum amplitude from sensor $\mathrm{S}_{2}$ to the maximum amplitude from sensor $\mathrm{S}_{1}$ after temperature loading at temperatures higher than $100{ }^{\circ} \mathrm{C}$

$r_{21, b}$ The ratio of the maximum amplitude from sensor $\mathrm{S}_{2}$ to the maximum amplitude from sensor $\mathrm{S}_{1}$ before temperature loading at temperatures higher than $100{ }^{\circ} \mathrm{C}$

$r_{3^{1}, a}$ The ratio of the maximum amplitude from sensor $\mathrm{S}_{3}$ to the maximum amplitude from sensor $\mathrm{S}_{1}$ after temperature loading at temperatures higher than $100{ }^{\circ} \mathrm{C}$

$r_{31, b}$ The ratio of the maximum amplitude from sensor $\mathrm{S}_{3}$ to the maximum amplitude from sensor $\mathrm{S}_{1}$ before temperature loading at temperatures higher than $100{ }^{\circ} \mathrm{C}$

$R_{21} \quad R_{21}=r_{21, a} / r_{21, b}$

$R_{31} \quad R_{31}=r_{31, a} / r_{31, b}$

$T$ Temperature

\section{ACKNOWLEDGEMENTS}

This outcome has been achieved with the financial support of the Czech Science Foundation under project No. 16-18702S "AMIRI - Aggregate-Matrix-Interface Related Issues in Silicate-based Composites". Besides the funding project, the controlled temperature loading of the test specimen was carried out under the thorough supervision of technician Pavel Kropáček at Institute of Physics, Faculty of Civil Engineering, Brno University of Technology.

\section{REFERENCES}

[1] P.-C. Aïtcin, S. Mindess. Sustainability of concrete. Modern concrete technology. Spon Press, New York, 2011.

[2] A. M. Neville. Properties of Concrete. Pearson Education Limited, Essex, 2011.
[3] I. Hager. Behaviour of cement concrete at high temperature. Bulletin of The Polish Academy of Science 61(1):145-154, 2013.

[4] S. Lim. Effects of elevated temperature exposure on cement based composite materials (doctoral dissertation), 2015.

[5] B. L. Karihaloo. Fracture Mechanics and Structural Concrete. Concrete Design and Construction. Longman Scientific \& Technical, New York, 1995.

[6] S. Kumar, S. V. Barai. Concrete Fracture Models and Applications. Springer, Berlin, 2011.

[7] J. Farran. Contribution mineralogique a l'etude de l'adherence entre les constituants hydrates des ciments et les materiaux enrobes. Revue des Materiaux de Construction (490-491,492):155-157,191-209, 1956.

[8] RILEM. Interfacial transition zone in concrete. In RILEM State-of-the-art Report. E \& FN Spon, London, 1996.

[9] RILEM. Second International Conference on the Interfacial Transition Zone in Cementitious Composites. E \& FN Spon, New York, 1998.

[10] K. L. Scrivener, A. K. Crumbie, P. Laugesen. The interfacial transition zone (ITZ) between cement paste and aggregate in concrete. Interface Science 12(4):411-421, 2014.

[11] G. Prokopski, J. Halbiniak. Interfacial transition zone in cementitious materials. Cem Concr Res 30(4):579-583, 2004.

[12] J. P. Ollivier, J. C. Maso, B. Bourdette. Interfacial transition zone in concrete. Advn Cem Bas Mat 2(1):30-38, 1995.

[13] N. J. Carino. The impact-echo method: an overview. In 2001 Structures Congress $\& 3$ Exposition. 2001. DOI:10.1061/40558(2001)15

[14] ČSN EN 196-1. 2016 methods of testing cement Part 1: Determination of strength.

[15] B. 1881. Testing concrete - part 119 method for determination of compressive strength using portions of beams broken in flexure (equivalent cubemethod), 1983. 